\title{
A cross sectional study of psychiatric morbidity in children of alcohol dependent fathers
}

\author{
Karegaonkar Abhijeet M. ${ }^{1}$, Arun Kumar V ${ }^{2}$ \\ ${ }^{1}$ Post-Doctoral Fellow in Child and Adolescent Psychiatry (CMC, Vellore), Assistant Professor, Dr. \\ Vasantrao Pawar Medical College, Hospital and Research Centre, Adgaon, Nashik. \\ ${ }^{2}$ Deputy Commandant / Specialist Medical Officer (Psychiatry), Composite Hospital, Border Security \\ Force, Tekanpur, Gwalior District, Madhya Pradesh.
}

Corresponding author: Karegaonkar Abhijeet M

Email - dr.kare.abhi@gmail.com

\begin{abstract}
Background: Children of Alcoholics (COAs) form a large but heterogeneous group. Along with genetic predisposition to develop dependence, COAs may inherit other comorbid mental disorders, that the alcohol dependence syndrome often presents with. Prevalence of psychiatric morbidity in children in general have been reported to be around $6.46 \%$ in Indian studies. Studies done with COAs have shown mixed findings, reporting both internalizing, externalizing and other behaviour problems. With dearth of Indian studies assessing psychiatric morbidity in COAs, a study was conducted to assess same.

Methodology: A cross sectional study was conducted in private de-addiction centre in South India. Sixtyfive children in age group of 6 to 18 years, whose fathers were admitted for alcohol dependence syndrome, were assessed along with their primary care giver using a semi-structured socio-demographic proforma and Kiddie-Schedule for Affective Disorder and Schizophrenia-Present and Lifetime version. Chi square and independent samples test were used as appropriate.

Results: $55.4 \%$ of the children had some lifetime psychiatric diagnosis. Around $21.5 \%$ of children had more than one lifetime diagnoses. Most common disorders found were anxiety disorders followed by mood disorders. Comparison of socio-demographic variables with respect to presence or absence of any lifetime psychiatric diagnosis, anxiety disorders, mood disorders and multiple diagnoses did not reveal any significant differences.

Conclusion: Psychiatric morbidity in COAs was higher than in children in general population as reported in other studies. Having alcohol dependent males in de-addiction centres provides an avenue for early detection and treatment of psychiatric morbidity in their children.
\end{abstract}

Keywords: Psychiatric disorders, Child and adolescent, Alcohol dependence

(Paper received $-8^{\text {th }}$ June 2021, Peer review completed $-5^{\text {th }}$ July 2021, Accepted $-10^{\text {th }}$ July 2021)

\section{INTRODUCTION}

Worldwide, children of alcohol dependent parents (COAs) form a large but heterogeneous group of population. They are at high risk of developing various psychological issues and illnesses [1]. The ecological model of family functioning states that the child outcome is influenced by a range of factors in the environment [2]. The Diathesis-Stress Model of developmental psychopathology in COAs implies that, alcoholism in parents influences child outcome biologically as well as psycho-socially [3].

Being an off-spring of a psychoactive-substance-dependent parent poses a genetic predisposition for the child to develop dependence [4-8]. Alcohol dependence syndrome often presents with various other co-morbid psychiatric illnesses and disorders [9-11]. In addition to that, parental substance misuse is highly disruptive 
to family functioning [12]. Most children growing with an alcoholic parent are subject to neglect, child abuse and maltreatment. Guilt, anger, anxiety, inability to form close relationships, confusion, embarrassment and depression are some of the psychological issues faced by COAs [13].

Earlier Indian studies report the prevalence of psychiatric morbidity in children in general, to be ranging from $2.6 \%$ to $35.6 \%$ [14-17], while a multi-stage, multi-informant assessment study indicated the prevalence in age group of 4 to 16 years to be $12 \%$. Enuresis, specific phobias, hyper-kinetic disorder, stuttering and oppositional defiant disorder were more frequent diagnoses in this age group [18]. A meta-analysis of child and adolescent psychiatric disorders in India found the prevalence in community to be $6.46 \%$ and in the school to be $23.33 \%$ [19], while the National Mental Health Survey 2016 reported the prevalence to be $7.3 \%$ in the age group $13-17$ years [20].

Parental alcoholism is associated with increased incidence of child psychopathology [21]. It was found that alcohol abuse in father was a significant socio-demographic correlate of psychiatric disorders in children as $20 \%$ (54/267) of children with alcohol abusing fathers had scores of $\geq 10$ on Childhood Psychopathology Measurement Schedule (CPMS) as compared to only 13\% (48/353) of children without alcohol abusing fathers [22].

About psychiatric morbidity in COAs, most studies give us only the areas of dysfunction, behavioural characteristics and increased risks. For example, an older review of studies revealed that COAs have problems in around 8 areas of outcomes viz. hyperactivity and conduct disorder; substance abuse, delinquency and truancy, cognitive functioning, social inadequacy, somatic problems, anxiety and depressive symptoms, physical abuse and dysfunctional family interaction [21]. An Indian study had found significantly more scores on conduct disorders, anxiety, physical illness with emotional problems and somatization in COAs than children of non-alcoholics (non-COAs) [23]. Another study reported COAs to have higher level of behavioural under-control and neuroticism and more psychiatric distress in relation to non-COAs [24]. COAs had scored significantly lower on Self Esteem Index, Adjustment Inventory Scores [25] and higher on Negative Emotionality [26] than non-COAs. Age and gender wise differences have also been reported [27-28]. However, only a couple of studies have looked for the prevalence of psychiatric morbidity among the COAs and found it to be 50\% [29-30]. Thus, as compared to studies for children in general, very few studies give prevalence of psychiatric morbidity in COAs and those on type of disorders in COAs have given varied findings. With these issues in mind, it was decided to conduct a study with the aim to study the lifetime psychiatric diagnoses in children of males diagnosed as having alcohol dependence syndrome admitted in private de-addiction centre.

\section{Objectives:}

- To study the socio-demographic characteristics of children

- To assess children for psychiatric diagnoses

- To study the differences between morbid and non-morbid children.

\section{METHODOLOGY}

It was a cross sectional study with children in age group of 6 to 18 years, whose fathers were diagnosed to have Alcohol Dependence Syndrome and were admitted in private de-addiction centre during the study period of three months. Approval from scientific and ethical committee was obtained. Serial sampling method was used. Child who did not assent and/or child who's Primary Care Giver (PCG) did not consent and / or child/PCG having any physical ailment sufficiently severe enough to affect the clinical interview were excluded from the study. Children of fathers having any other co-morbid substance use were excluded except for tobacco.

Socio-demographic data was collected using a semi-structured proforma. It included age-group, gender, education, birth order, who are they residing with, type of family, religion, type of residence (urban/rural) and who was the informant.

Kiddie Schedule for Affective Disorders and Schizophrenia for School Aged Children (6-18 Years) - Present and Lifetime Version (K-SADS-PL) was used for diagnostic interview [31]. Children and their PCG were interviewed with children first in most cases. K-SADS-PL has a screening interview and diagnostic 
supplements. Probes and objective criteria are given to rate individual symptoms. K-SADS-PL is administered by interviewing the child, parent(s), and finally achieving summary ratings. Interviewer may need to use best clinical judgment to assign the summary ratings. It allows us to make 5 different types of notes regarding a diagnosis, (viz., no information, not present, probable, in partial remission, definite). For the purpose of study, 'lifetime diagnosis / disorder' includes both present and / or lifetime illnesses. The child having at least one definite lifetime psychiatric disorder or having one in partial remission was considered as a 'morbid' child and the child with no lifetime diagnosis or a 'probable' (i.e. not confirmed) diagnosis or where no information was available about any diagnosis was considered as a 'non-morbid' child. All disorders were grouped into 11 broad diagnostic categories and children having multiple (more than one) diagnoses were also noted additionally.

\section{STATISTICAL ANALYSIS}

The analysis was done using statistical analysis software SPSS version 19. To test the association between socio-demographic variables (independent) any lifetime psychiatric diagnoses, lifetime diagnostic categories, multiple diagnoses (dependent), chi square and independent samples t test were used as appropriate.

\section{RESULTS AND DISCUSSION}

Table 1: Pattern of Psychiatric Diagnoses in children

\begin{tabular}{|c|c|c|}
\hline Morbidity & $\begin{array}{c}\text { Present } \\
\text { N (\%) }\end{array}$ & $\begin{array}{c}\text { Absent } \\
\text { N (\%) }\end{array}$ \\
\hline Any Lifetime Psychiatric Disorder & $36(55.4)$ & $29(44.6)$ \\
\hline Mood disorders & $23(35.4)$ & $42(64.6 \%)$ \\
\hline Schizophrenia \& other psychotic disorder & $0(0)$ & $65(100)$ \\
\hline Anxiety disorders & $27(41.5)$ & $38(58.5)$ \\
\hline Adjustment disorders & $1(1.5)$ & $64(98.5)$ \\
\hline Elimination disorders & $0(0)$ & $65(100)$ \\
\hline Eating disorders & $0(0)$ & $65(100)$ \\
\hline Disruptive behaviour disorders (ADHD, CD, ODD) & $1(1.5)$ & $64(98.5)$ \\
\hline Tic disorders & $0(0)$ & $65(100)$ \\
\hline Substance use disorders & $0(0)$ & $65(100)$ \\
\hline Mental Retardation & $1(1.5)$ & $64(98.5)$ \\
\hline Others & $1(1.5)$ & $64(98.5)$ \\
\hline Multiple Diagnoses (>1) & $14(21.5)$ & $51(78.5)$ \\
\hline
\end{tabular}

Around 87 children, whose fathers were admitted for alcohol dependence syndrome during the study period (three months), were contacted along with their PCG. Out of that, 16 did not fulfil criteria for age, two could not be interviewed due to their physical illness, three children's PCG denied consent and one child denied assent. Thus, 65 children could be included in the study. The mean age of children was ten years with little preponderance of females $(53.8 \%)$. Most of them (83\%) were studying in primary or secondary schools, while one was not studying. Nearly half were first born (50.8\%) and for most, mother was the PCG (90.8\%). Most children stayed with both parents (86.4\%), with $56.9 \%$ in nuclear family and $41.5 \%$ in joint family. Most were Hindu by religion (87.7\%); and nearly $2 / 3 \mathrm{rd}$ hailed from urban background $(66.2 \%)$. Of all, $55.4 \%(36 / 65)$ of children had some lifetime psychiatric diagnosis. Most common group of disorders found were anxiety disorders (41.5\%) followed by mood disorders (35.4\%), while $1.5 \%$ of the children had each adjustment disorders, disruptive behaviour disorders, mental retardation and disorders in 'others' category. None of them had schizophrenia \& other psychotic disorders, elimination disorders, eating disorders, tic disorders and substance use disorders. Around $21.5 \%$ of children had multiple diagnoses. The details are shown in Table 1. The socio-demographic variables were analysed with respect to a) presence or absence of any lifetime psychiatric diagnoses, b) presence or absence of lifetime diagnostic categories which were found more prevalent (viz., mood disorders and anxiety disorders) and c) having multiple diagnoses. No significant difference was found (Table 2). 
Table 2: Comparison of Socio-demographic characteristics with Diagnoses

\begin{tabular}{|c|c|c|c|c|c|c|c|c|c|c|}
\hline & \multicolumn{2}{|c|}{$\begin{array}{c}\text { Lifetime } \\
\text { diagnosis }\end{array}$} & \multicolumn{2}{|c|}{$\begin{array}{c}\text { Mood } \\
\text { Disorders }\end{array}$} & \multicolumn{2}{|c|}{$\begin{array}{c}\text { Anxiety } \\
\text { Disorders }\end{array}$} & \multicolumn{2}{|c|}{$\begin{array}{c}\text { Multiple } \\
\text { diagnoses }\end{array}$} \\
\hline & & & $\mathbf{Y}$ & $\chi^{2}$ & $\mathbf{Y}$ & $\chi^{2}$ & $\mathbf{Y}$ & $\chi^{2}$ & $\mathbf{Y}$ & $\chi^{2}$ \\
\hline \multicolumn{2}{|c|}{$\begin{array}{c}\text { Socio-demographic } \\
\text { characteristics }\end{array}$} & N (\%) & $\begin{array}{c}36 \\
(55.4)\end{array}$ & $\begin{array}{l}\text { df, } \\
\text { p }\end{array}$ & $\begin{array}{c}23 \\
(35.3)\end{array}$ & $\begin{array}{c}\text { df } \\
\text { p }\end{array}$ & $\begin{array}{c}27 \\
(41.5)\end{array}$ & $\begin{array}{c}\text { dft, } \\
\text { p }\end{array}$ & $\begin{array}{c}14 \\
(21.5)\end{array}$ & $\begin{array}{c}\text { df, } \\
\mathbf{p}\end{array}$ \\
\hline \multirow{2}{*}{ Age group } & 6-11 yrs & $35(53.8)$ & 18 & 0.48 & 10 & 1.54 & 15 & 0.05 & 5 & 2.36 \\
\hline & $12-18$ yrs & $30(46.2)$ & 18 & 0.48 & 13 & 0.24 & 12 & 0.82 & 9 & 0.12 \\
\hline \multirow{2}{*}{ Gender } & $\mathbf{M}$ & $30(46.2)$ & 17 & 0.04 & 11 & 0.04 & 11 & 0.54 & 5 & 0.78 \\
\hline & $\mathbf{F}$ & $35(53.8)$ & 19 & $\begin{array}{c}1 \\
0.84\end{array}$ & 12 & $\begin{array}{c}1 \\
0.84 \\
\end{array}$ & 16 & $\begin{array}{c}1 \\
0.46\end{array}$ & 9 & $\begin{array}{c}1 \\
0.38 \\
\end{array}$ \\
\hline \multirow{4}{*}{ Education } & Primary & $27(41.5)$ & 12 & \multirow{4}{*}{$\begin{array}{c}2.83 \\
3 \\
0.50\end{array}$} & 6 & \multirow{4}{*}{$\begin{array}{c}4.5 \\
3 \\
0.21\end{array}$} & 9 & & 3 & \multirow{4}{*}{$\begin{array}{c}3.48 \\
3 \\
0.32\end{array}$} \\
\hline & Secondary & $27(41.5)$ & 17 & & 12 & & 15 & 4.19 & 8 & \\
\hline & Higher & $10(15.4)$ & 6 & & 5 & & 3 & 3 & 3 & \\
\hline & Uneducated & $1(1.5)$ & 1 & & 0 & & 0 & & 0 & \\
\hline \multirow{5}{*}{ Birth Order } & 1 & $33(50.8)$ & 20 & \multirow{5}{*}{$\begin{array}{c}2.76 \\
4 \\
0.6\end{array}$} & 14 & \multirow{5}{*}{$\begin{array}{c}2.31 \\
4 \\
0.68\end{array}$} & 15 & & 8 & \multirow{5}{*}{$\begin{array}{c}0.89 \\
4 \\
0.92\end{array}$} \\
\hline & 2 & $22(33.8)$ & 11 & & 7 & & 8 & 2.11 & 4 & \\
\hline & 3 & $8(12.3)$ & 4 & & 2 & & 4 & 4 & 2 & \\
\hline & 4 & $1(1.5)$ & 1 & & 0 & & 0 & 0.72 & 0 & \\
\hline & Adopted & $1(1.5)$ & 0 & & 0 & & 0 & & 0 & \\
\hline \multirow{3}{*}{$\begin{array}{l}\text { Staying } \\
\text { with } \\
\text { parents }\end{array}$} & Single & $4(6.2)$ & 3 & \multirow{3}{*}{$\begin{array}{c}1.09 \\
2 \\
0.6\end{array}$} & 1 & \multirow{3}{*}{$\begin{array}{c}0.77 \\
2 \\
0.68\end{array}$} & 2 & 0.35 & 0 & \multirow{3}{*}{$\begin{array}{c}1.59 \\
2 \\
0.45\end{array}$} \\
\hline & Both & $55(84.6)$ & 29 & & 19 & & 22 & 2 & 12 & \\
\hline & Others & $6(9.2)$ & 4 & & 3 & & 3 & 0.84 & 2 & \\
\hline \multirow{3}{*}{ Family } & Nuclear & $37(56.9)$ & 20 & \multirow{3}{*}{$\begin{array}{c}1.43 \\
2 \\
0.5\end{array}$} & 13 & \multirow{3}{*}{$\begin{array}{c}0.58 \\
2 \\
0.75\end{array}$} & 16 & 0.76 & 8 & \multirow{3}{*}{$\begin{array}{c}0.28 \\
2 \\
0.87\end{array}$} \\
\hline & Joint & $27(41.5)$ & 16 & & 10 & & 11 & 2 & 6 & \\
\hline & Others & $1(1.5)$ & 0 & & 0 & & 0 & 0.68 & 0 & \\
\hline \multirow{3}{*}{ Religion } & Hindu & $57(87.7)$ & 31 & \multirow{3}{*}{$\begin{array}{c}0.36 \\
2 \\
0.84\end{array}$} & 20 & \multirow{3}{*}{$\begin{array}{c}1.66 \\
2 \\
0.44\end{array}$} & 23 & 0.27 & 12 & \multirow{3}{*}{$\begin{array}{c}1.05 \\
2 \\
0.59\end{array}$} \\
\hline & Muslim & $2(3.1)$ & 1 & & 0 & & 1 & 2 & 0 & \\
\hline & Christian & $6(9.2)$ & 4 & & 3 & & 3 & 0.87 & 2 & \\
\hline \multirow{2}{*}{ Residence } & Rural & $22(33.8)$ & 14 & \multirow{2}{*}{$\begin{array}{c}0.92 \\
1 \\
0.39\end{array}$} & 8 & 0.01 & 10 & 0.21 & 3 & 1.23 \\
\hline & Urban & $43(66.2)$ & 22 & & 15 & $\begin{array}{c}1 \\
0.91\end{array}$ & 17 & $\begin{array}{c}1 \\
0.65\end{array}$ & 11 & $\begin{array}{c}1 \\
0.27\end{array}$ \\
\hline & Mother & $59(90.8)$ & 31 & 2.09 & 21 & 0.01 & 23 & 1.72 & 13 & 0.09 \\
\hline PCG & Others & $6(9.2)$ & 5 & $\begin{array}{c}1 \\
0.15\end{array}$ & 2 & $\begin{array}{c}1 \\
0.91\end{array}$ & 4 & $\begin{array}{c}1 \\
0.19\end{array}$ & 1 & $\begin{array}{c}1 \\
0.76\end{array}$ \\
\hline
\end{tabular}

[PCG: Primary Care Giver, Y: Present, df: Degree of Freedom] Socio-demographic characteristics of children were compared with respect to presence or absence of any lifetime psychiatric diagnosis, mood disorders, anxiety disorders and multiple diagnoses using Chi square test. No significant associations were found]

Table 3: Comparison of Means Ages with Diagnoses

\begin{tabular}{|c|c|c|c|c|c|}
\hline & & N (\%) & Mean & SD & $t, p^{*}$ \\
\hline \multirow{2}{*}{$\begin{array}{l}\text { Lifetime } \\
\text { Diagnosis }\end{array}$} & $\mathrm{Y}$ & $36(55.4)$ & 11.22 & 3.62 & \multirow{2}{*}{$0.91,0.37$} \\
\hline & $\mathrm{N}$ & $29(44.6)$ & 10.38 & 3.83 & \\
\hline \multirow{2}{*}{$\begin{array}{c}\text { Mood } \\
\text { disorder }\end{array}$} & $\mathrm{Y}$ & $23(35.4)$ & 11.83 & 3.86 & \multirow{2}{*}{$1.59,0.12$} \\
\hline & $\mathrm{N}$ & $42(64.6)$ & 10.31 & 3.56 & \\
\hline \multirow{2}{*}{$\begin{array}{l}\text { Anxiety } \\
\text { disorder }\end{array}$} & $\mathrm{Y}$ & $27(41.5)$ & 10.96 & 3.50 & \multirow{2}{*}{$0.21,0.83$} \\
\hline & $\mathrm{N}$ & $38(58.5)$ & 10.79 & 3.91 & \\
\hline \multirow{2}{*}{$\begin{array}{c}\text { Multiple } \\
\text { Diagnoses }\end{array}$} & $\mathrm{Y}$ & $14(21.5)$ & 12.29 & 3.89 & \multirow[t]{2}{*}{$1.66,0.10$} \\
\hline & $\mathrm{N}$ & $51(78.5)$ & 10.45 & 3.60 & \\
\hline
\end{tabular}

$\left[{ }^{*}\right.$ Degree of freedom $\left.=63\right]$. ( $Y=$ Present, $N=$ Absent, $S D=$ Standard Deviation). Mean ages of children were compared with respect to presence or absence of any lifetime psychiatric diagnosis, anxiety disorders, mood disorders and multiple diagnoses using independent samples t test. None were statistically significant. 
Children having any lifetime psychiatric diagnoses, mood disorder and multiple diagnoses seemed to be 11.5 years older than those who did not have them while no such difference was seen for anxiety disorders. However, these differences were not statistically significant (Table 3).

\section{DISCUSSION}

\section{Socio-demographic characteristics}

The study population belonged to age groups of 6-18 years with mean of 10 years, more or less equally distributed with respect to gender and age group (viz., childhood and adolescence), most were upto $2^{\text {nd }}$ born, had mother as PCG as well as the informant was, were staying with both parents, Hindu by religion and hailed from urban background.

\section{Morbidity in children}

The study showed that around $55.4 \%$ of the children had some lifetime psychiatric morbidity. The finding is similar to other studies that found around $50 \%$ morbidity among COAs, one among which used the same diagnostic instrument [29-30]. This is higher than the morbidity reported in children in general population like the MECA study [32] (20.9\%) and much higher than that reported in a meta-analysis of Indian studies [19]. Thus, it seems that the children of alcohol dependents have higher psychiatric morbidity than children in general. In our study, anxiety disorders (41.5\%) were the most common group of disorders followed by mood disorders $(35.4 \%)$ while $1.5 \%$ of children had each adjustment disorders, disruptive behaviour disorders, mental retardation and disorders in 'others' category. An epidemiological study of child and adolescent psychiatric disorders had reported 6.2\% non-organic enuresis, $2.9 \%$ specific isolated phobia, $1.6 \%$ having hyper-kinetic disorder and $1.5 \%$ stuttering in the children of age group of $4-16$ years with lesser prevalence of other disorders [18]. One study had reported most of their children (19.6\%) having specific isolated phobia, $12 \%$ non-organic sleep disorders, $11.5 \%$ tension headache, $6 \%$ hyper-kinetic disorder, $5.5 \%$ pica, $4.5 \%$ enuresis, $7.5 \%$ sleep terror and $3.3 \%$ with epilepsy [33].

The high prevalence of anxiety disorders in our study seems to be similar to the prevalence in that of children in general. In specific population of COAs, a study had found mainly depression and anxiety disorder prevalent among COAs [29], the finding similar to our study. However, other studies on COAs had reported externalizing disorders to be commoner than internalizing disorders [27,34]. The instrument we used (i.e. K-SADS-PL) may explain these findings. It was noted that K-SADS-PL had the best test-retest reliability for anxiety disorders and Affective Disorders among the diagnostic interviews and also that the children appeared to be better informants describing their mental states (internalizing disorders) [35]. We also found $21.5 \%$ of children had two or more diagnoses which was more than $15.2 \%$ reported elsewhere [30].

\section{Comparison of children}

While almost $55 \%$ of children had some lifetime morbidity, it is worth to note that remaining $45 \%$ did not have any. This is in concordance with the observation that in spite of harbouring an increased risk of developing alcohol use disorders and other forms of psychopathology, not all children of alcohol dependent fathers develop them [3]. Comparison among the children neither revealed any significant difference between mean ages, nor any relation of age group of the child, gender, education, birth order, 'whom they stay with', type of family, religion, type of residence (urban/rural) and Primary Care Giver (informant) with presence or absence of any lifetime psychiatric diagnosis, mood disorders, anxiety disorders or those with multiple diagnoses. A study of children in general population had reported differences in prevalence of psychiatric illnesses according to age group [22,27] and socioeconomic status [22] but not as per type-offamily [33] while mixed findings are seen regarding birth order [22,33,36] and gender [18, 22-23]. On other hand, in specific population of COAs, presence of a psychiatric diagnosis was neither related to age nor the gender [29]. Thus, regarding socio-demographic differences among morbid and non-morbid children, given the mixed findings in children in general population and with paucity of studies in specific population of COAs, it will be prudent to restrict any comment and keep this area open for further study. 


\section{Strengths of the study}

- The study was first of its kind in this population, in this setting. One study had studied psychological characteristics but not psychiatric diagnoses [25].

- The study evaluated for a host of psychiatric disorders commonly seen in children through direct face-to-face interviews with the child and parent.

\section{Limitations of the study}

- Small sample size: A large sample size could have compensated for diagnosis missed or absent in this study, but which are shown to be common in this type of study population by previous studies.

- Lack of control sample: In presence of the increased percentage of morbid children (55.4\%), lack of control sample restricts the comments on its significance.

- Psychiatric Morbidity in PCG: Many studies have also looked for and ruled out psychiatric morbidity in PCG [30,34] which can be a confounding factor in their observation and reporting of the child, and this may be one of the reason for high morbidity in the study. Studies which did not assess for morbidity in caregivers or fathers, have shown findings similar to our study [29].

- Interviewer bias: K-SADS-PL is a semi-structured, "interviewer based" interview schedule where the interviewer has to use his/her clinical skills to interpret the information and use it for the diagnostic clarification. The interviewer in this study was not blinded to the purpose of study. This may have caused bias in evaluating the children, giving them diagnoses that have the possibility of being revised or corrected after more detailed evaluation on more number of visits, with structured interviews ('respondent based') or questionnaires, and detailed clinical evaluation.

- The findings of this study may not be generalized to the community because the study was conducted in a private psychiatric hospital.

\section{Recommendations}

- Further research in a more generalized setting, with a large sample size to cover the disorders with prevalence of less than $1 \%$ in children in general population, along with a control sample would be able to comment more emphatically on the relevance of higher prevalence of psychiatric morbidity in children of alcohol dependent fathers found in this study.

- Evaluating caregivers and ruling out psychiatric morbidity will remove an important confounding factor and add to the value of the study.

- Given the psycho-social impact of alcoholism on family, the de-addiction treatment should also include at least evaluative sessions with the children and spouse.

- Though alcohol use and dependence disorders were not found in this study, heritability of alcoholism has been noted [37]. Educating children about harmful effects of alcohol and their biological predisposition to develop dependence can be a method of primary prevention of alcohol use disorders. Young adults may avoid drinking when they perceive their parent(s) to be alcoholic, and consequently perceive themselves to be at elevated risk for alcoholism [38].

\section{CONCLUSION}

The overall view that the children of alcohol dependents are a vulnerable group and that there is a need for their evaluation is supported by the study. Psychiatric morbidity in children of fathers diagnosed as having alcohol dependence syndrome was found to be higher than the morbidity in children in general population noted in other studies. More than half the sample had some lifetime psychiatric diagnosis. Most common disorders were anxiety disorders followed by mood disorders. No significant differences were seen in sociodemographic characteristics of children with respect to presence or absence of lifetime diagnosis, anxiety disorders, mood disorders and multiple diagnoses. The findings of the study are similar to those studies which employed almost similar methodology, though few in number, whereas it differs from those using other methodologies involving personality profile and ruling out co-morbidity in primary care givers, quantitative assessment of childhood psychopathology, multiple informants and so on. 
Thus, it seems prudent to make an attempt to evaluate the COAs for any psychopathology and having alcohol dependent males in de-addiction centres provides an avenue for early detection and treatment of psychiatric morbidity in their children.

\section{REFERENCES}

1. Sher KJ. Psychological characteristics of children of alcoholics. Alcohol Health Res World 1997;(21):247-54.

2. Sroufe L, Rutter M. Developmental psychopathology: Concepts and challenges. Dev Psychopathol 2000;3(12):265-96.

3. Windle M. Concepts and Issues in COA Research. Alcohol Health Res World 1997;21(3):185-91.

4. Merikangas KR, Stevens DE, Fenton B, Stolar M, O'Malley S, Woods SW. Co-morbidity and familial aggregation of alcoholism and anxiety disorders. Psychol Med 1998;28(4):773-88.

5. Heath AC, Bucholz KK, Madden PA, Dinwiddie SH, Slutske WS, Bierut LJ, et al. Genetic and environmental contributions to alcohol dependence risk in a national twin sample: consistency of findings in women and men. Psychol Med 1997;27(6):1381-96.

6. Kendler KS, Prescott CA, Neale MC, Pedersen NL. Temperance board registration for alcohol abuse in a national sample of Swedish male twins, born 1902 to 1949. Arch Gen Psychiatry 1997;54(2):178-84.

7. McGue M, Elkins I, Iacono WG. Genetic and environmental influences on adolescent substance use and abuse. Am J Med Genet 2000;96(5):671-7.

8. Tsuang MT, Lyons MJ, Eisen SA, Goldberg J, True W, Lin N, et al. Genetic influences on DSM-III-R drug abuse and dependence: a study of 3,372 twin pairs. Am J Med Genet 1996;67(5):473-7.

9. Kisore P, Lal N, Trivedi JK, Dalal PK, Aga VM. A Study of Comorbidity in Psychoactive Substance Dependence Patients. Indian J Psychiatry 1994;36(3):133-7.

10. Vohra AK, Yadav BS, Khurana H. A Study of Psychiatric Comorbidity in Alcohol Dependence. Indian J Psychiatry 2003;45(4):247-52.

11. Singh NH, Sharma S, Pasweth A. Psychiatric co-morbidity among alcohol dependants. Indian J Psychiatry 2005;47(4):222-6.

12. Dawe S, Australian National Council on Drugs. Drug use in the family: impacts and implications for children. 2007.

13. Children Of Alcoholics - 17 [Internet]. [cited 2021 Feb 25]. Available from: https://www.aacap.org/aacap/Families_and_Youth/Facts_for_Families/FFF-Guide/Children-OfAlcoholics-17.aspx

14. Anita, Gaur DR, Vohra AK, Subash S, Khurana H. Prevalence Of Psychiatric Morbidity Among 6 To 14 Years Old Children. Indian J Community Med 2003;28(3):133-8.

15. Malhotra S, Kohli A, Arun P. Prevalence of psychiatric disorders in school children in Chandigarh, India. Indian J Med Res 2002;116:21-8.

16. Deivasigamani TR. Psychiatric Morbidity in Primary School Children: An Epidemiological Study. Indian J Psychiatry 1990;32(3):235-40.

17. Lal N, Sethi BB. Estimate of mental ill health in children of an urban community. Indian J Pediatr 1977;44(350):55-64.

18. Srinath S, Girimaji SC, Gururaj G, Seshadri S, Subbakrishna DK, Bhola P, et al. Epidemiological study of child \& adolescent psychiatric disorders in urban \& rural areas of Bangalore, India. Indian J Med Res 2005;122(1):67-79.

19. Malhotra S, Patra BN. Prevalence of child and adolescent psychiatric disorders in India: a systematic review and meta-analysis. Child Adolesc Psychiatry Ment Health 2014;8(1):22-9.

20. Gururaj G, Varghese M, Benegal V, Rao GN, Pathak K, Singh LK, Mehta RY, Ram D, Shibukumar TM, Kokane A, Lenin Singh RK, Chavan BS, Sharma P, Ramasubramanian C, Dalal PK, Saha PK, Deuri SP, Giri AK, Kavishvar AB, Sinha VK, Thavody J, Chatterji R, Akoijam BS, Das S, Kashyap A, Ragavan VS, Singh SK, Misra R and NMHS collaborators group. National Mental Health Survey of India, 2015-16: Prevalence, patterns and outcomes. Bengaluru, National Institute of Mental Health and Neuro Sciences, NIMHANS Publication No. 129, 2016

21. West MO, Prinz RJ. Parental alcoholism and childhood psychopathology. Psychol Bull 1987;102(2):204-18.

22. Rahi M, Kumavat AP, Garg S, Singh MM. Socio-demographic co-relates of psychiatric disorders. Indian J Pediatr 2005;72(5):395-8.

23. Narang RL, Gupta R, Mishra BP, Mahajan R. Temperamental Characteristics and Psychopathology Among Children of Alcoholics. Indian J Psychiatry 1997;39(3):226-31. 
24. Sher KJ, Walitzer KS, Wood PK, Brent EE. Characteristics of children of alcoholics: putative risk factors, substance use and abuse, and psychopathology. J Abnorm Psychol 1991;100(4):427-48.

25. Stanley S, Vanitha C. Psychosocial correlates in adolescent children of alcoholics- implications for intervention.: (a study from India). Int J Psychosoc Rehabil 2008;12(2):67-80.

26. Elkins IJ, McGue M, Malone S, Iacono WG. The Effect of Parental Alcohol and Drug Disorders on Adolescent Personality. Am J Psychiatry 2004;161(4):670-6.

27. Hill SY, Shen S, Lowers L, Locke-Wellman J, Matthews AG, McDermott M. Psychopathology in offspring from multiplex alcohol dependence families with and without parental alcohol dependence: A prospective study during childhood and adolescence. Psychiatry Res 2008;160(2):155-66.

28. Morgan PT, Desai RA, Potenza MN. Gender-related influences of parental alcoholism on the prevalence of psychiatric illnesses: Analysis of the National Epidemiologic Survey on Alcohol and Related Conditions. Alcohol Clin Exp Res 2010;34(10):1759-67.

29. Ratsma JE, Van der Brink W, Van der Stelt O, Gunning WB. Psychiatric disorders in children of treated alcoholics: the influence of gender, parental psychiatric co-morbidity and family history of alcoholism. In: Biological vulnerability to alcoholism in children of alcoholics [Internet]. University of Amsterdam; 2001 [cited $2021 \mathrm{Feb} 25]$. Available from: https://dare.uva.nl/search?identifier=6666d3ca-3a7e-4b0e-8aad-9ec1e6fd488e

30. Se CK, Mf U, S O. [Psychopathology in children of alcoholic fathers]. Turk Psikiyatri Derg Turk J Psychiatry 2006;17(1):3-11.

31. Kaufman J, Birmaher B, Brent D, Rao U, Flynn C, Moreci P, et al. Schedule for Affective Disorders and Schizophrenia for School-Age Children-Present and Lifetime Version (K-SADS-PL): initial reliability and validity data. J Am Acad Child Adolesc Psychiatry 1997;36(7):980-8.

32. Shaffer D, Fisher P, Dulcan MK, Davies M, Piacentini J, Schwab-Stone ME, et al. The NIMH Diagnostic Interview Schedule for Children Version 2.3 (DISC-2.3): description, acceptability, prevalence rates, and performance in the MECA Study. Methods for the Epidemiology of Child and Adolescent Mental Disorders Study. J Am Acad Child Adolesc Psychiatry 1996;35(7):865-77.

33. Bansal PD, Barman R. Psychopathology of school going children in the age group of 10-15 years. Int J Appl Basic Med Res 2011;1(1):43-8.

34. Raman V, Prasad S, Appaya MP. Children of men with alcohol dependence: Psychopathology, neurodevelopment and family environment. Indian J Psychiatry 2010;52(4):360-6.

35. Renou S, Hergueta T, Flament M, Mouren-Simeoni M-C, Lecrubier Y. [Diagnostic structured interviews in child and adolescent's psychiatry]. L'Encephale 2004;30(2):122-34.

36. Offord DR, Boyle MH, Szatmari P, Rae-Grant NI, Links PS, Cadman DT, et al. Ontario Child Health Study: II. Six-Month Prevalence of Disorder and Rates of Service Utilization. Arch Gen Psychiatry 1987;44(9):8326.

37. Haber JR, Jacob T, Heath AC. Paternal Alcoholism and Offspring Conduct Disorder: Evidence for the "Common Genes" Hypothesis. Twin Res Hum Genet 2005;8(2):120-31.

38. Haller MM, Chassin L. The Reciprocal Influences of Perceived Risk for Alcoholism and Alcohol Use Over Time: Evidence for Aversive Transmission of Parental Alcoholism. J Stud Alcohol Drugs 2010;71(4):588-96.

$* * * * * * * * * * * * * * * * * * * * * * * * * * * * * * * * * * * *$

Acknowledgements - Nil

Conflict of Interest - Nil

Funding - Nil 